\title{
Desenvolvimento profissional: Proposição de um modelo conceitual
}

Luciana Mourão. Universidade Salgado de Oliveira

Ana Cláudia Monteiro. Universidade Salgado de Oliveira

\section{Resumo}

As constantes mudanças no mercado de trabalho têm demandado cada vez mais qualificação profissional das pessoas e contribuído para relevância das investigações sobre a compreensão do fenômeno Desenvolvimento Profissional. Assim, o presente estudo teve como objetivo realizar uma análise conceitual do Desenvolvimento Profissional, que é uma técnica indicada para processos de refinamento teórico. O resultado desse estudo identificou que há grande convergência entre o que se chama de Desenvolvimento Profissional no senso comum e a forma como o termo é entendido no contexto científico. O conceito é bastante utilizado nas áreas de Educação, Administração e Psicologia e está associado a crescimento, progressão, aumento de capacidades e competências.

Palavras-chave: análise conceitual; desenvolvimento profissional; qualificação, aprendizagem; carreira.

\begin{abstract}
Professional development: Proposal of a conceptual model. The constant changes in the job market have demanded people's increasing professional qualification and contributed to the relevance of research to understand the phenomenon Professional Development. This study aimed to carry out a conceptual analysis of Professional Development, which is a technique indicated for theoretical refinement processes. The result of this study has identified that there is great convergence between what is called Professional Development in common sense and the way the term is understood in the scientific context. The concept is widely used in the areas of Education, Administration and Psychology and is associated with growth, progression, capacity building and skills.
\end{abstract}

Keywords: conceptual analysis; professional development; qualification; learning; career.

\section{Resumen}

Desarrollo profesional: Proposición de un modelo conceptual. Los constantes cambios en el mercado de trabajo demandan cada vez más, calificación profesional de las personas, lo que contribuye para la relevancia de las investigaciones sobre la comprensión del fenómeno Desarrollo Profesional. Por lo tanto, el presente estudio tuvo como objetivo realizar un análisis conceptual del Desarrollo Profesional, que es una técnica indicada para los procesos de refinamiento teórico. El resultado de este estudio identificó que existe una gran convergencia entre lo que se denomina Desarrollo Profesional en el sentido común y la forma como el término es entendido en el contexto científico. El concepto se utiliza bastante en las áreas de Educación, Administración y Psicología y está asociado al crecimiento, progresión, aumento de capacidades y competencias.

Palabras clave: análisis conceptual; desarrollo profesional; calificación; aprendizaje; carrera. 
Com a aceleração da produção de conhecimentos e dinamicidade dos ambientes laborais a temática do Desenvolvimento Profissional (DP) vem ganhando relevância e novos contornos. Embora resultados de pesquisas revelem um aumento expressivo nos estudos na última década (Monteiro \& Mourão, 2017), o tema ainda é incipiente na literatura nacional e estrangeira (Hill, Beisiegel, \& Jacob, 2013; Monteiro \& Mourão, 2017). Para possibilitar melhor entendimento do conceito e dos usos que se faz do mesmo, este estudo apresenta uma análise conceitual do DP, uma vez que tal análise é um método indicado para processos de refinamento teórico.

Três subconjuntos de atividades do método científico permitem clarificar conceitos e realizar refinamentos teóricos: a experimentação, a matematização e a análise conceitual (Machado \& Silva, 2007). Esta última é considerada a principal atividade no método científico, por anteceder a experimentação e a matematização ou mesmo excluí-las quando elas se revelarem cientificamente inadequadas (Petocz \& Newbery, 2010). Portanto, a investigação da lógica do uso de um determinado conceito é importante por permitir um fortalecimento epistemológico do campo, uma vez que a filosofia da linguagem reflete sobre até que ponto as nomenclaturas atribuídas às variáveis correspondem às suas características intrínsecas (Coelho-Junior, Meneses, Almeida, \& Bernardo, 2015).

Para proceder à análise conceitual no presente artigo, nos baseamos nos métodos apresentados por Ryle (1970) e Wilson (2005), a partir de um processo organizado em cinco etapas consecutivas, a saber: (i) a seleção de um conceito de interesse; (ii) a identificação de usos e atributos do conceito; (iii) os relacionamentos com outros conceitos; (iv) a construção de casos-modelos; e (v) a identificação de antecedentes e consequentes. As seções deste artigo correspondem, portanto, a cada uma dessas etapas, sendo também apresentadas considerações finais que sintetizam os resultados do trabalho de análise conceitual realizado.

\section{Seleção do Conceito de Desenvolvimento Profissional}

A primeira etapa de uma análise conceitual consiste na seleção de um conceito de interesse. A escolha do DP como temática de estudo relaciona-se à emergência do tema, tendo em vista a intensa competitividade entre as organizações e entre os profissionais, que tem marcado os ambientes de trabalho nas últimas décadas (Coelho \& Mourão, 2011).
A escolha deste conceito guarda relação com o fato de ser um termo muito usado na prática, quer seja das pessoas ou das organizações de trabalho, mas com poucas pesquisas científicas. Por um lado, considera-se, assim, que é relevante a busca de maior compreensão acerca de seu conceito, pois essa discrepância entre o uso geral do termo e o uso na academia pode estar relacionada à associação do termo a outros conceitos. Em outras palavras, é possível que aquilo que se chama de DP no senso comum esteja recebendo outra nomenclatura no contexto científico. Por outro lado, na última década, observa-se um expressivo crescimento da literatura nacional e estrangeira nas pesquisas sobre este tema.

Fica, então, um questionamento se há de fato um novo conceito que começa a ser explorado ou se trata apenas de uma variação vocabular para conceitos que já vinham sendo tratados a partir de outras nomenclaturas. Para responder a essa pergunta, o primeiro passo seria o de identificar os usos e atributos do DP, conforme será discutido a seguir.

\section{A Identificação de Usos e Atributos do Desenvolvi- mento Profissional}

A segunda etapa do processo de análise de conceito diz respeito à identificação de usos e atributos do conceito. Para tanto, foi feita uma análise dos termos "desenvolvimento" e "profissional" nos dicionários Aurélio, Houaiss e Michaelis. Nos três dicionários, o conceito do termo "desenvolvimento" é semelhante, estando relacionado ao ato ou efeito de desenvolver; aumento, progresso, crescimento. Entretanto, a definição dos dicionários Houaiss e Michaelis apresenta elementos não encontrados no Aurélio. O Houaiss associa o conceito a aumento de qualidades morais, psicológicas, intelectuais etc e o Michaelis, cita termos como capacidade ou competência e inclui os termos amadurecimento e evolução. O termo desenvolvimento possui significados em diferentes campos do conhecimento, apontados nos dicionários Michaelis e Houaiss. O dicionário Michaelis apresenta o conceito atrelado à religião, economia, geometria, matemática, ecologia, música e topografia, enquanto o dicionário Houaiss traz significados específicos para as áreas de música e economia.

Em relação ao termo "profissional" nos três dicionários o conceito se relaciona com uma determinada profissão, ofício. No Dicionário Aurélio, o conceito também é utilizado para designar pessoas: "Que faz uma

Estudos de Psicologia, 23(1), janeiro a março de 2018, 33-45 
coisa por ofício" (Ferreira, 2001). No Michaelis a definição de profissional é: "Que exerce uma ocupação como meio de vida ou para ganhar dinheiro" (Weiszflog, 2015), enquanto no Houaiss tem-se "aquele que exerce por profissão determinada atividade" (Houaiss \& Villar, 2009).

Chama a atenção o fato de os dicionários Houaiss e Michaelis relacionarem o termo também à atividade, o que confere uma visão mais ampla ao termo profissional. O dicionário Michaelis inclui ainda o caráter pejorativo atribuído ao termo quando ele é usado para tratar como profissão qualquer atividade, pelo lucro que obtém ou pela prática sistemática.

A análise desses conceitos mostra que o desenvolvimento não está associado exclusivamente a crescimento, embora seja tantas vezes associado a crescimento na carreira. Os conceitos remetem a aspectos mais amplos como progressão, evolução, propagação. Além disso, incluem elementos como aumento das competências ou capacidades ou mesmo aumento de qualidades, sejam elas, morais, psicológicas ou intelectuais. Portanto, mesmo sem a inclusão do termo "profissional", o termo desenvolvimento já apresenta associação com um processo de mudança evolutiva. Quando o dicionário Michaelis apresenta a definição da palavra desenvolvimento como "passagem gradual (da capacidade ou possibilidade) de um estágio inferior a um estágio maior, superior, mais aperfeiçoado" fica clara a possibilidade de a aprendizagem e a mudança - em seus sentidos amplos - estarem associadas ao termo desenvolvimento entendido como algo que muda para melhor, daí a associação com adiantamento, aumento, crescimento, expansão, progresso.

O termo profissional, por sua vez, não apresenta nenhuma relação direta com emprego ou organização de trabalho. Os dicionários tampouco mencionam o termo carreira. Eles fazem menção à profissão, ofício, atividades, formação. Há em tais definições um caráter de distinção do que é característico de um determinado ofício, com o sentido de que os ofícios ou profissões apresentam atividades e práticas sistemáticas que lhe são específicas.

A análise dos termos separadamente mostra que a junção dos mesmos já seria esperada pelo que se apresenta no próprio conceito de desenvolvimento, posto que um dos desenvolvimentos possíveis às pessoas fosse justamente o desenvolvimento no campo profissional. Assim, o conceito apresentado na literatura da área não se dissocia muito do conceito existente no senso comum, posto que o DP é descrito como o crescimento e amadurecimento do conhecimento, das habilidades e das atitudes do trabalhador, adquiridos ao longo da vida e resultantes de ações formais ou informais de aprendizagem no trabalho (Mourão, PuentePalacios, Porto, \& Monteiro, 2015). Tal conceito reflete, portanto, um processo de qualificação, de aquisição e evolução das competências laborais.

Mas além de analisar o conceito e os significados atribuídos ao DP, é importante também que sejam investigados seus usos em diferentes campos do conhecimento. Nesse caso, é importante analisar especialmente três campos: Educação, Administração e Psicologia, com usos distintos do conceito, embora algumas vezes complementares.

No campo da Educação, o DP focaliza a formação, a aquisição e o desenvolvimento de competências. A discussão do DP no campo educacional ocorre não somente em cursos de natureza técnica, claramente voltados para a formação profissional, mas na própria discussão do papel da Educação Básica, em especial, o Ensino Médio, bem como na Educação Superior, em suas diferentes etapas.

No que diz respeito à Educação Básica, a discussão sobre formação profissional inicia-se, sobretudo, no Ensino Médio, que ainda não tem no Brasil uma identidade clara sobre o seu papel em termos de preparação para a continuação dos estudos (formação propedêutica) ou preparação para o trabalho (formação profissional) (Zibas, 2005). Uma análise dos diferentes modelos de ensino médio realizada por Castro (2008) aponta que o modelo brasileiro difere do norte-americano (escolas com cursos semelhantes, em que os alunos podem escolher parte das disciplinas que querem cursar) e também difere do modelo europeu (escolas com cursos diferentes, já direcionados para formação profissional específica). No modelo brasileiro há menor ênfase no planejamento da vida profissional, pois os estudantes não têm como optar por diferentes tipos de escolas, tampouco por escolhas pessoais de formação dentro das escolas. O único caminho para um DP no Ensino Médio seria o de optar por cursos técnicos.

Além da Educação Básica, a discussão do DP, no campo da Educação, também continua ocorrendo no Ensino Superior em seus diferentes níveis. A graduação tem o claro propósito de formação de um profissional. A pós-graduação lato sensu, por sua vez, está voltada para a especialização e atualização profissional. E mesmo a pós-graduação stricto sensu, que incialmente era voltada para a formação de mestres e doutores, com a criação dos mestrados profissionais passou a assumir também um papel mais claro no DP (Coordenação de 
Aperfeiçoamento de Pessoal de Nível Superior [Capes], Portaria Normativa $n^{\circ}$ 17/2009).

No contexto educacional, além da ênfase na formação dos estudantes, há também um uso bastante comum do termo na preparação dos professores, com o entendimento de que o processo intencional e contínuo destinado a melhorar o conhecimento profissional, as destrezas e as atitudes dos educadores terão reflexos na melhoria da aprendizagem dos alunos (Guskey, 2000). A partir dessa lógica, os estudos acerca do DP são bastante explorados pela área da Educação, em especial no que se refere ao desenvolvimento de professores (Hill et al., 2013; Monteiro \& Mourão, 2017). Assim, é possível encontrar uma vasta literatura acerca do seu conceito na área da Educação, ao contrário do que acontece em outros setores de trabalho.

O desenvolvimento profissional de docentes é considerado como o processo pelo qual os professores, no papel de agentes de mudanças, revêem, renovam e ampliam individual ou coletivamente os propósitos do ensino, adquirem e desenvolvem de forma crítica o conhecimento, as destrezas e a inteligência emocional essenciais para a reflexão e as práticas profissionais, em cada fase da vida laboral (Day, 2001). Nessa mesma linha, Ponte (1994) acrescenta que nesse processo o professor reconhece a necessidade de crescimento e de aquisições diversas, atribuindo a si próprio o papel fundamental para o seu desenvolvimento.

Esse processo de DP seria, pois, caracterizado por acréscimos de conhecimento, atitudes e competências dos professores (Sparks \& Loucks-Horsley, 1990). Nesse sentido, o conceito está relacionado a um amadurecimento do profissional e à reflexão e melhoria do seu saber fazer, derivado de experiências formais e informais de aprendizagem (Day, 2001).

No campo da Administração, o foco está na carreira, na empregabilidade e no desempenho no trabaIho. De fato, desenvolver competências no trabalho tornou-se um conceito central para compreender as mudanças que passaram a ocorrer no sistema de desenvolvimento das pessoas (Gondim, Souza, \& Peixoto, 2013). Assim, o conceito de DP assume um sentido amplo no ambiente laboral e refere-se a um conjunto de ações de indução de aprendizagem para ajudar a organização e as pessoas a atingirem os seus objetivos. O desenvolvimento estaria associado, pois, tanto a ações de aprendizagem que ocorrem formalmente no ambiente de trabalho, como também a ações de aprendizagem informal, que decorrem das experiências cotidianas dos trabalhadores (Coelho \& Mourão, 2011; Flach \& Antonello, 2010; Mourão et al., 2015).

Destarte, a aprendizagem nas organizações divide-se em dois tipos: a natural ou informal, e a induzida ou formal (Abbad \& Borges-Andrade, 2014). Tais aprendizagens também são consideradas como explícita ou implícita, respectivamente (Sonnentag, Niessen, \& Ohly, 2004). A primeira ocorre por meio de tentativa e erro, por imitação, observação, na busca de ajuda com colegas no cotidiano laboral, nos arquivos de materiais escritos e nos contatos informais com pares, superiores, fornecedores e parceiros de trabalho. A segunda diz respeito a situações estruturadas, planejadas pelas organizações e/ou pelos trabalhadores, para potencializar os processos de aquisição, retenção e generalização de competências.

O processo de amadurecimento profissional, associado à experiência laboral e ao crescimento das pessoas em suas fases de DP associa-se à aquisição e aperfeiçoamento de conhecimentos, habilidades e atitudes. Tal processo, por sua vez é considerado, em muitos casos, como preditores do desempenho no trabalho e da condição de empregabilidade.

O surgimento do conceito de empregabilidade, que compreende um conjunto de competências e habilidades necessárias para uma pessoa conquistar e manter um trabalho ou emprego (Campos, 2011), fez crescer a preocupação das pessoas com o seu desenvolvimento profissional. Segundo Aranha (2001, p. 281), "por empregabilidade entende-se a responsabilização do trabalhador pela obtenção e manutenção do seu emprego, através de um processo contínuo de formação e aperfeiçoamento". Diante desse novo cenário de responsabilização dos trabalhadores, o DP passa a ser foco não apenas das organizações, mas também dos indivíduos que buscam garantir sua empregabilidade a partir do desenvolvimento de competências que os coloquem em uma posição favorável no mercado de trabalho.

Dessa forma, é exigido do trabalhador que ele se mantenha atualizado e aberto a novos conhecimentos para que diante de tantas transformações possa conhecer e aplicar os novos significados ao mundo do trabaIho (Abbad, Loiola, Zerbini, \& Borges-Andrade, 2013). Assim é que, do trabalhador do século XXI, exige-se mais do que o conhecimento específico das tarefas de um posto de trabalho. Esses trabalhadores precisam ser plurais, dominar os saberes específicos de uma determinada área do conhecimento e, simultaneamente, ter

Estudos de Psicologia, 23(1), janeiro a março de 2018, 33-45 
visão sistêmica que Ihe permita fazer adaptações no seu fazer laboral. Portanto, o mundo do trabalho atual requer que os trabalhadores possuam múltiplas competências para que haja o DP, destacando-se: aprender a conhecer, a fazer, a viver junto com outras pessoas e a ser (Abbad et al., 2013).

Por fim, no campo da Psicologia o termo "desenvolvimento profissional" mescla conceitos advindos da Educação e da Administração, pois consiste da construção de conhecimento e de competências a partir tanto do processo de formação, como da prática profissional, com reflexos na práxis e nas interações sociais no ambiente de trabalho (Barbier, Chaix, \& Demailly, 1994). O conceito inclui processos individuais amplos, como as transformações identitárias dos indivíduos, além das competências coletivas desenvolvidas ao longo da trajetória profissional (Paquay, Wouters, \& Van Nieuwenhoven, 2012).

Em outro conceito de "desenvolvimento profissional" a referência volta-se para o processo individual de aprendizagem de conhecimentos, habilidades e atitudes. Em tal processo o indivíduo aprende pela experiência laboral - um aprendizado pelo e para o trabalho (Paquay et al., 2012).

Em uma síntese dos conceitos apresentados pelos dicionários e pela literatura da área, é possível fazer uma análise que destaca o uso dos seguintes vocábulos: transformação, identidade, competências, trajetória, processo, indivíduo, coletividade, conhecimentos, habilidades e atitudes, aprendizagem, construção, prática, interações sociais, ambiente e trabalho. Do ponto de vista de uma análise temática, poder-se-ia agrupar tais vocábulos em três conjuntos de elementos ou dimensões: (i) transformação / trajetória / processo / construção; (ii) competências / conhecimentos / habilidades / atitudes / aprendizagem / identidade / prática / trabalho; e (iii) indivíduo / coletividade / ambiente / interações sociais.

O primeiro grupo de vocábulos está mais relacionado à palavra desenvolvimento e evidencia que a sua natureza é processual, ou seja, algo que acontece ao longo do tempo e que está associado a uma construção, mudança, caminho percorrido, trajetória, transformação, crescimento, evolução, maturação. O segundo grupo de elementos volta-se para o termo profissional, pois refere-se ao objeto da mudança, isto é, o que muda com o desenvolvimento (os conhecimentos, as habilidades, as atitudes, as competências decorrentes de uma aprendizagem e de uma prática que afeta o trabalho, a identidade e a atuação do profissional). Por fim, o terceiro e último grupo de elementos associa-se aos contextos e às formas em que ocorre esse processo de transformação de competências que pode ter caráter individual ou coletivo, partindo das interações sociais e da relação estabelecida com o ambiente.

Como se depreende dessa análise conceitual, o DP não necessariamente está associado ao contexto das organizações, pois ele ocorre com pessoas que têm ou não vínculo empregatício. A descrição do conceito refere-se a um fenômeno que envolve os trabaIhadores de modo geral, sejam eles ligados ao mercado formal de trabalho, autônomos ou pertencentes ao mercado informal. As características centrais do conceito estão associadas, portanto, a um processo de aprendizagem relacionada às atividades de trabalho ou à profissão. Tais características aproximam-se do conceito de DP no Dicionário de Psicologia da American Psychological Association - APA (VandenBos, 2010, p. 274), que define o termo como "a educação ou treinamento continuado que é esperado ou requerido de pessoas empregadas em uma profissão".

Assim, seguindo a metodologia proposta, após a análise do uso e atributos do conceito, é importante identificar outros conceitos possíveis relacionados ao DP. Essa etapa será descrita a seguir, a partir de uma abordagem das principais áreas que estudam a temática.

\section{Os Relacionamentos do Desenvolvimento Profissional com outros Conceitos}

A terceira etapa da análise conceitual diz respeito ao estabelecimento de relacionamentos com outros conceitos. No dicionário da APA, o termo aparece associado a Desenvolvimento de Carreira, que é entendido como a maneira pela qual a pessoa gerencia a sua carreira, dentro e/ou entre organizações; e as maneiras pelas quais a organização estrutura o progresso profissional de seus empregados, os recompensando com variados benefícios à medida que eles se tornem mais habilidosos e experientes (VandenBos, 2010).

Observa-se uma diferença entre os conceitos de DP e Desenvolvimento na Carreira (apresentado por VandenBos, 2010, no Dicionário da APA). O primeiro seria a resultante da aprendizagem relacionada ao trabalho, envolvendo um processo de desenvolvimento de competências. Já o Desenvolvimento na Carreira, nessa visão mais ortodoxa, compreenderia outros aspectos como progressão na organização e decisões de mudança de área de atuação. Mas as diferenças entre tais conceitos ficam menores quando se consideram definições mais abrangentes de carreira como 
a apresentada por Donald Super no modelo do Arco Normando (Super, 1990). Em tal teoria, o conceito de carreira é associado a dois pilares. Um de base biológica - representando as dimensões pessoais (influência da personalidade e das escolhas profissionais) e o outro de base geográfica - representando as dimensões sociais (influência das condições socioeconômicas e do contexto de forma mais ampla). Tais pilares seriam integrados pelos construtos de aprendizagem social e tomada de decisão (Oliveira, Melo-Silva, \& Coleta, 2012). Nesse sentido, o conceito de carreira estaria próximo ao de $\mathrm{DP}$, tendo, ambos, a aprendizagem relacionada ao trabalho como elemento central.

Essa percepção de proximidade desses conceitos seria corroborada pelo trabalho realizado por Ambiel (2014), que apontou que a teoria desenvolvimental de carreira, iniciada por Donald Super, embora ainda careça de integração, teve avanços teóricos e ganhou novos contornos com a Teoria de Construção de Carreira (Savickas, 2013) e o modelo Life Designing (Savickas et al., 2009). Nessa perspectiva mais contemporânea de carreira, há, então, uma atitude ativa por parte do trabalhador em termos da construção e desenvolvimento de sua trajetória, que vai além de uma sequência de ocupações, compreendendo também as significações de suas vivências (Ambiel, 2014). Nesse sentido, considerando a Teoria Social Cognitiva de Desenvolvimento de Carreira (Lent, Brown, \& Hackett, 1994), há uma ênfase no papel de agente que os indivíduos exercem no processo de desenvolvimento de carreira, bem como em fatores contextuais que aprimoram ou restringem essa atuação.

Retomando a definição de DP da APA, observa-se que a análise do conceito de DP permite identificar o uso de palavras como "educação" e "treinamento continuado" que conferem o caráter processual desse conceito, posto que trata de um crescimento que não tem um fim esperado, é contínuo. Além disso, o conceito também se associa a "profissão", ou seja, denota o desenvolvimento de conhecimentos e competências que são específicas a uma determinada categoria ocupacional. O uso da expressão "pessoas empregadas" na definição apresentada no dicionário, por um lado, reforça a importância atribuída às organizações de trabalho nesse processo de desenvolvimento; por outro lado, exclui, equivocadamente, trabalhadores autônomos ou informais. Médicos, dentistas, psicólogos, vendedores e tantos outros profissionais autônomos ou informais também apresentam um processo de DP que não estaria contemplado em tal definição.

Observa-se, então que a definição de DP no dicionário da APA aproxima-se bastante do conceito de "desenvolvimento de carreira", que é inclusive um conceito indicado para ser consultado de forma complementar e/ou diferencial. A definição que o referido dicionário apresenta para "desenvolvimento de carreira" apresenta duas vertentes - o planejamento do indivíduo e o da organização. Na primeira, a definição de desenvolvimento de carreira é a "maneira pela qual a pessoa gerencia o progresso de sua carreira, tanto dentro de uma organização quanto entre organizações. As questões que os indivíduos precisam enfrentar em seu desenvolvimento profissional diferem em função de estarem no estágio inicial, intermediário ou final de sua carreira" (VandenBos, 2010, p. 273).

O conceito de carreira apresentado no dicionário da APA exclui aqueles que não têm um vínculo com uma organização de trabalho, pois fala de um progresso "dentro de uma organização ou entre organizações". Tal restrição ao conceito de carreira é contrária ao que indica a literatura da área que aponta possibilidades de tipos de carreira que abrangem pessoas que regem seu avanço profissional sem, necessariamente, passar por vínculos com organizações de trabalho (Baruch, 2004; Magalhães \& Bendassolli, 2013). Nesse sentido, a definição apresentada pelo dicionário técnico da APA apresenta uma vertente bastante voltada para a Psicologia Organizacional, considerando os vínculos estabelecidos entre indivíduos e organizações e desconsiderando profissionais como um microempreendedor, por exemplo.

Mas, se por um lado, o conceito de DP apresenta menos similitudes com o conceito de carreira objetiva que reflete a sequência dos papéis ocupados pelo indivíduo ao longo da vida de trabalho (Hall, 1976; Magalhães \& Bendassolli, 2013); por outro lado, apresenta convergências com o conceito de carreira subjetiva - que se refere à interpretação pessoal dos papéis e das experiências de trabalho pelos trabalhadores (Magalhães \& Bendassolli, 2013). Esse último conceito propõe uma dimensão temporal e remete a um processo de transformação identitária que coincide com o conceito de Paquay et al. (2012) sobre o DP.

Além do conceito de carreira, o DP também apresenta clara associação com o conceito de competências, que foi proposto por McClelland, em 1973, como uma forma de compreender melhor a escolha de atividades profissionais das pessoas na expectativa de avançar em

Estudos de Psicologia, 23(1), janeiro a março de 2018, 33-45 
relação aos testes de inteligência. A partir dos estudos de Le Boterf (1994) e de Zarifian (2001), o conceito de competência passou a ser entendido como agregação de valor, sendo o indivíduo - e não mais o cargo - o elemento central do conceito (Dutra, 2004). O elemento conceitual de agregação de valor presente no conceito de competência guarda relação direta com o conceito de DP que também prevê um processo de agregação de valor ao longo da vida laboral das pessoas.

Além disso, a definição de Perrenoud (1999) para competências traz outro elemento que também aproxima os conceitos de DP e competência, que é a relação com o desempenho no trabalho. Assim, competência compreende "uma capacidade de agir eficazmente em um determinado tipo de situação, apoiada em conhecimentos, mas sem limitar-se a eles" (Perrenoud, 1999, p. 7). Essa ideia de uma ação eficaz apoiada em conhecimentos seria uma espécie de comprovação de que a pessoa é competente ou que ela se desenvolveu profissionalmente, aproximando, pois, esses dois conceitos.

Destarte, os conceitos de competências e de desenvolvimento de carreira são aqueles que apresentam uma relação mais direta com o DP. E na continuidade da metodologia de análise conceitual, observa-se que a identificação dos usos e atributos do conceito, associada à análise de outros conceitos a ele relacionados, viabiliza a identificação e/ou construção de modelos de DP, que é o tema da próxima seção.

\section{A Construção de um Modelo Teórico para o Desen- volvimento Profissional}

A quarta etapa da análise conceitual diz respeito à construção de casos ou modelos, que podem ser extraídos da realidade, da literatura ou construídos pelo pesquisador (Walker \& Avant, 1988). Apesar de o presente estudo ser eminentemente teórico, para a análise do DP optou-se por construir também um modelo extraído da realidade, e para tanto foi feita uma pequena pesquisa com profissionais da área e trabalhadores em geral.

$\mathrm{Na}$ amostra com o grupo de especialistas da área (acadêmicos e profissionais que estudam e/ou trabaIham com a temática do DP), participaram 10 pessoas com idade média de 38,2 anos ( $D P=9,3$ ), sendo sete do sexo feminino e o nível de escolaridade predominante foi pós-graduação. Já a amostra formada por trabalhadores de diversas outras áreas (comércio, educação, telecomunicações, militar e jurídica), foi composta por 22 pessoas com idade média de 37,7 anos ( $D P=11,09)$,
$64 \%$ do sexo feminino e predomínio do ensino médio (73\%) como nível de escolaridade.

Aos participantes de ambos os grupos foi entregue uma folha com uma pergunta única, a saber: o que você entende por desenvolvimento profissional? Não foi dada nenhuma orientação quanto ao tamanho ou direção da resposta. A coleta de dados foi realizada individualmente com cada um dos participantes. Todos foram informados de que a pesquisa visava conhecer o entendimento que as pessoas tinham acerca do conceito de DP. Os resultados foram analisados por dois juízes independentes que marcaram palavras-chave que eram associadas ao DP, quer seja pelos especialistas da área, quer seja pelos trabalhadores em geral. A listagem de palavras dos dois públicos não teve divergência entre os juízes, possivelmente porque a tarefa deles era simplesmente apontar todas as palavras mencionadas.

O resultado da análise do DP na visão de especialistas da área mostra que: a maioria dos pesquisados (9) relacionou o DP às habilidades, capacidades e competências profissionais. Apenas um dos pesquisados associou o conceito ao desenvolvimento na carreira e no cargo e outro fez associação do DP para atuação em qualquer área.

Os especialistas remetem o conceito de DP não só a busca, aprimoramento, aquisição de conhecimentos para melhoria de seu desempenho, como também à percepção de quais são os pontos a serem melhorados. Apenas três especialistas associaram o DP às ações educacionais, citando as aprendizagens formais (cursos de qualificação profissional, graduação, palestras, treinamentos oferecidos pela empresa) e informais (leituras, aprendizagem experiencial, trocas com colegas e pares, rede network).

Já na visão dos profissionais de outras áreas, o DP está relacionado não só a busca, aprimoramento, aquisição de conhecimentos para melhoria do desempenho no trabalho, como também à ampliação, acréscimo, aperfeiçoamento e reciclagem dos mesmos. De uma forma mais frequente que os especialistas, os profissionais pesquisados relacionam o DP ao crescimento profissional, evolução e ascensão na carreira. As ações educacionais foram citadas pela maioria dos pesquisados, que sinalizaram com maior recorrência as aprendizagens advindas de uma composição de ações formais e informais (54\%), do que as atividades caracterizadas exclusivamente como ações formais (36\%).

Uma análise global das definições dadas por especialistas e trabalhadores aponta para mais similitudes 
do que discrepâncias. Contudo, a visão dos especialistas apresenta um caráter mais abstrato envolvendo competência, busca, aprimoramento, enquanto os profissionais são voltados para aspectos mais concretos como evolução e ascensão na carreira e ações formais e informais de aprendizagem.

A partir da análise desses resultados é possível sistematizar um modelo de DP. Esse modelo é caracterizado como um processo que se inicia com a identificação do objetivo profissional almejado, considerando uma perspectiva de identidade profissional e perspectiva profissional futura. Nesse sentido, tal processo guarda correspondência ao conceito de carreira subjetiva previamente discutido (Magalhães \& Bendassolli, 2013).

Se for admitida uma intencionalidade nesse processo, ou seja, um planejamento do DP, o próximo passo seria a análise das necessidades de formação e desenvolvimento de competências, que tem como produto final um plano de aprendizagem. Essa etapa envolveria, portanto, o levantamento de competências profissionais necessárias para se atingir o objetivo almejado e, simultaneamente, um levantamento das lacunas de competências considerando o estágio atual de amadurecimento profissional da pessoa. O referido plano de aprendizagem deve ser composto, portanto, por diferentes ações voltadas à melhoria, aprimoramento $e$ aquisição das habilidades e capacidades indispensáveis para o desempenho das atividades laborais almejadas. Ele remete a aspectos de reflexão, assimilação e transformação da aprendizagem (Kolb, 1984).

A participação em ações que impulsionem a aquisição, aprimoramento, ampliação, acréscimo, aperfeiçoamento e reciclagem de conhecimentos relativos às competências exigidas para a atividade completam esse modelo de DP. Essas ações envolvem o desenvolvimento não só de processos cognitivos, mas também afetivos, perceptivos e comportamentais a partir de uma perspectiva holística e integrativa da aprendizagem experiencial (Kolb, 1984). Nesse sentido, as ações de DP compreendem um processo de transformação contínua da experiência a partir da interação social como elemento essencial dessa transformação (Illeris, 2007). De acordo, sobretudo com os trabalhadores pesquisados e também com a literatura da área (Mourão, Monteiro, \& Viana, 2014), as ações de aprendizagem podem ocorrer de maneira formal (por meio de cursos de qualificação profissional, graduação, treinamentos corporativos etc.) ou de maneira informal (a partir das experiências cotidianas de trabalho, interação com os pares, leitura de livros, etc.).

No processo de DP, a elaboração e implementação de um plano de aprendizagem devem conduzir - em médio e longo prazos, a depender do plano estabelecido - a uma identificação de progressos que retroalimentam o sistema. Tais progressos podem ser identificados a partir da análise de indicadores de carreira que podem envolver assunção de novas responsabilidades, novas posições ou papéis no ambiente de trabalho, ampliação da rede profissional, ganhos financeiros etc. A identificação desses progressos permite uma redefinição de metas pessoais e profissionais, que se possibilita uma abertura a novos cenários e possibilidades, num processo contínuo de crescimento.

A Figura 1 representa o modelo de DP proposto, evidenciando o seu caráter processual e cíclico, confirmando o que a literatura apresenta acerca de uma aprendizagem ao longo da vida (Borges-Andrade, Zerbini, Abbad, \& Mourão, 2013). Tal modelo permitiria uma espiral cíclica de crescimento, na linha do que foi previsto por Nonaka e Takeuchi (1997) relativamente à Gestão do Conhecimento.

O modelo apresentado assume um caráter genérico no sentido de que pode ser atribuído a diferentes categorias laborais. Assim, não é um modelo especificamente voltado para carreiras de profissões específicas como médicos, advogados, engenheiros, músicos ou qualquer outra. Tal característica lhe confere ampla aplicação e possibilidades de estudo. Tem como elementos centrais o fato de prever um processo cíclico, envolver escolhas como ponto de partida, prever processos amplos de aprendizagem, estar voltado para o caráter subjetivo de carreira e considerar uma transformação baseada na interação.

Uma vez construído um modelo de DP cabe apresentar uma análise de variáveis antecedentes e consequentes associadas a tal construto. Esse processo foi conduzido a partir da análise de duas revisões de literatura sobre o DP realizadas por Hill et al. (2013) e Monteiro e Mourão (2017). A primeira revisão apresenta um balanço das pesquisas sobre o tema nos últimos 20 anos e uma sinalização de possíveis caminhos futuros. Já a segunda revisão ampliou a busca de estudos empíricos nacionais e estrangeiros e apresentou a rede nomológica do conceito, possibilitando a realização do último passo da análise conceitual, que será o objeto central da próxima seção.

Estudos de Psicologia, 23(1), janeiro a março de 2018, 33-45 


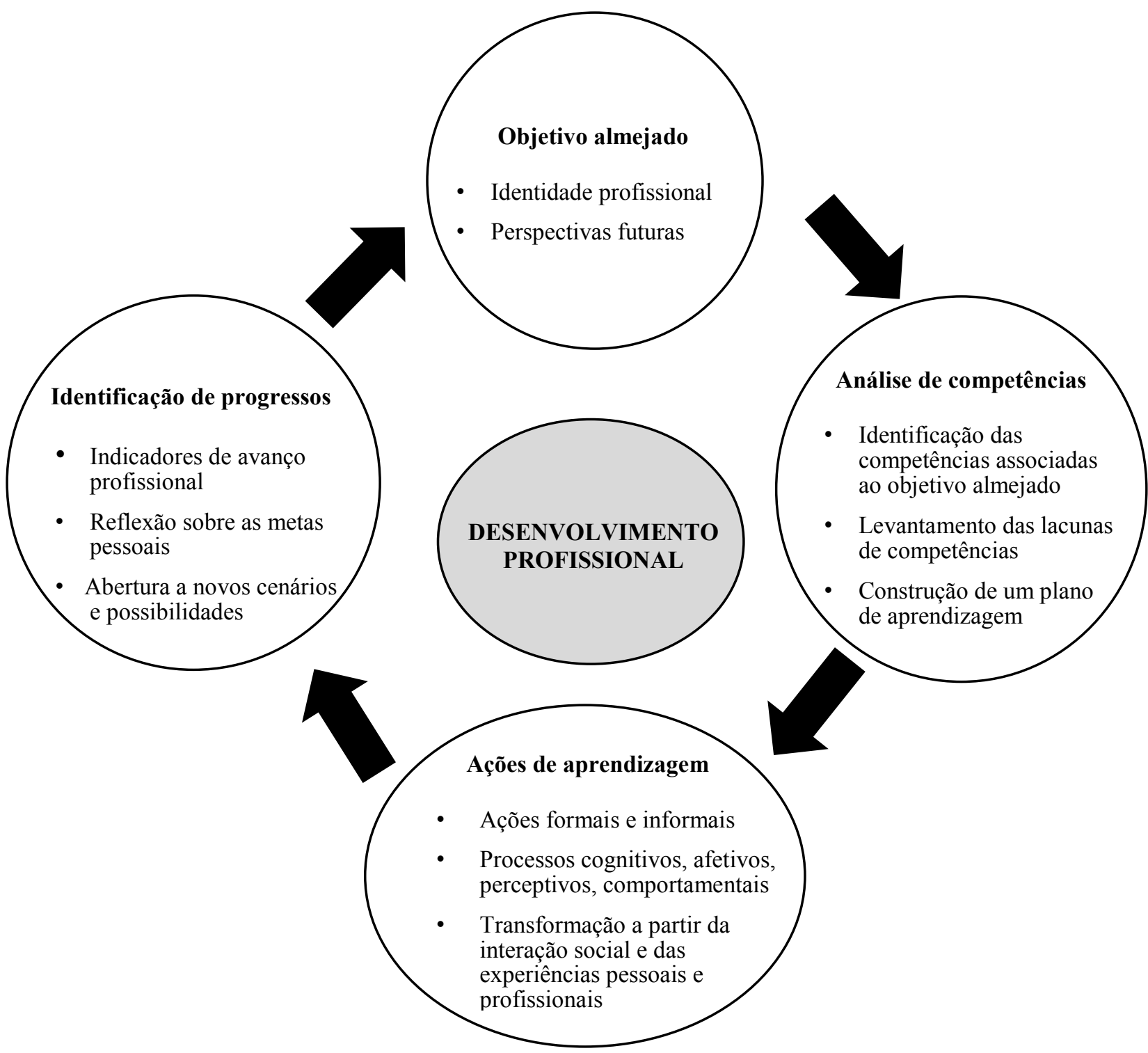

Figura 1. Modelo de Desenvolvimento Profissional Construído após Análise de Resultado de Pesquisa de Profissionais da Área e de Trabalhadores em Geral.

\section{Antecedentes e Consequentes do Desenvolvimento Profissional}

A quinta e última etapa da análise conceitual diz respeito à investigação dos antecedentes e consequentes do DP. O levantamento das variáveis relacionadas ao conceito permite compreender a sua rede nomológica, mas os estudos acerca da investigação dessa rede na literatura nacional e estrangeira ainda são incipientes. Assim, foi analisada a revisão de literatura sobre DP recentemente apresentada por Monteiro e Mourão (2017) trazendo os principais antecedentes e consequentes do DP. As autoras realizaram uma pesquisa no Google Scholar, com uso do software Harzing Publish or Perish, pesquisando 514 artigos em inglês e português, no período de 1994 a 2014.

A análise dos resumos ou textos completos realizados na revisão de Monteiro e Mourão (2017) mostra que tanto variáveis pessoais quanto profissionais podem atuar como antecedentes do DP. Além disso, o estudo aponta que ainda são raras as pesquisas que consideram o DP como preditor, sendo mais frequente o construto figurar como consequente. As principais variáveis antecedentes do DP listadas pelas autoras 
seriam: mentoring, grupos de estudos colaborativos, programas formativos, pesquisa-ação, conhecimento do conteúdo, eficácia, crenças, coaching e atitudes. A análise dessas variáveis mostra que o DP é favorecido tanto por ações formais quanto informais de aprendizagem (Mourão et al., 2015), havendo também espaço para características individuais do trabalhador (como as crenças, as atitudes e a autoeficácia), corroborando as reflexões de Lent et al. (1994) e Ambiel (2014).

Em relação às variáveis consequentes do $\mathrm{DP}$, a revisão de Monteiro e Mourão (2017) aponta um único estudo desenvolvido por Mourão et al. (2014), que mostra a satisfação no trabalho como uma decorrência do DP. Esse estudo corroborou com os achados de Santos e Mourão (2011), que apontam a satisfação no trabalho como consequência do impacto das ações de treinamento (um dos elementos do DP). Nesse sentido, observa-se um interesse maior em compreender o que leva ao DP (variáveis antecedentes) do que entender as decorrências advindas de tal desenvolvimento (variáveis consequentes).

Um estudo que merece destaque por, apresentar um modelo de DP, é o de Ho, Nakamori e Ho (2013). Os autores apontam a gestão do conhecimento como antecedente do DP de professores de educação básica, considerando quatro processos: co-criação por método participativo, internalização, compartilhamento e avaliação de conhecimento. Esse estudo se destaca por apresentar um processo completo de DP, considerando seu ciclo evolutivo.

Assim, após investigação dos antecedentes e consequentes do DP, fica evidenciada a necessidade de ampliação das pesquisas de sua rede nomológica, para que seja possível compreender melhor o fenômeno, conforme sinalizado na revisão de literatura realizada por Monteiro e Mourão (2017). Vale registrar que na literatura revisada não foi encontrado nenhum estudo que investigasse variáveis mediadoras e moderadoras na relação com o DP. O fato de não haver modelos em que tal construto modere ou medeie as relações entre tais variáveis, reforça a importância de um aprofundamento nos estudos sobre DP, uma vez que ele se refere a um fenômeno do cotidiano das pessoas (Kolb, 1984; Paquay et al., 2012) e que muito provavelmente apresenta possibilidade de contribuição para explicar a relação entre variáveis do indivíduo e do mundo do trabalho. A realização da presente análise conceitual pode ser útil para impulsionar novas pesquisas nesse sentido, pois amplia o entendimento do fenômeno e de suas interfaces com outros construtos.

\section{Considerações finais}

O objetivo deste estudo foi realizar uma análise conceitual do DP a fim de aumentar a compreensão acerca do fenômeno. Identificou-se que há grande convergência entre o que se chama de DP no senso comum e a forma como o termo é entendido no contexto científico. Para leigos ou pesquisadores da área, o termo é associado a processos de crescimento e amadurecimento do conhecimento, das habilidades e das atitudes do trabalhador, adquiridos ao longo da vida e resultantes de ações formais ou informais de aprendizagem no trabalho.

A análise do conceito realizada contribuiu para clarificar a compreensão do fenômeno, possibilitando esclarecimentos acerca do uso e dos atributos do DP, assim como seu relacionamento com outros conceitos. A comparação das definições de DP em diferentes dicionários permitiu identificar que o termo "desenvolvimento" é associado a aumento, progresso, crescimento, aumento de qualidades morais, psicológicas, intelectuais, capacidade ou competência, amadurecimento e evolução. Já o termo "profissional" apresentou como atributos essenciais: profissão, ofício, atividade, cursos profissionais e escola profissional, sendo as duas últimas citadas exclusivamente no dicionário Aurélio.

Podemos concluir que a expressão DP é bastante utilizada nas áreas de Educação, Administração e Psicologia. $\mathrm{Na}$ Educação, o foco está na formação, aquisição e desenvolvimento de competências profissionais, com foco a partir do Ensino Médio. Na Administração, a pesquisa mostra que o foco está na carreira, na empregabilidade e no desempenho no trabalho, estando o DP associado à realização de ações formais e informais de aprendizagem no ambiente de trabalho ou fora dele. Por fim, na Psicologia, o termo engloba tanto elementos conceituais advindos da Educação (construção de conhecimento e de competências a partir do processo de formação) como também da Administração (com foco prática profissional e nas interações sociais no ambiente de trabalho). Além disso, a Psicologia contribui com as reflexões de que o DP inclui processos individuais, como as transformações identitárias e as subjetividades que permeiam a trajetória das pessoas.

Em relação ao resultado da investigação sobre antecedentes e consequentes, concluímos que os estudos da rede nomológica do DP ainda são incipientes, sendo investigados quase que somente os preditores do fenômeno. Possíveis variáveis moderadoras, mediadoras ou consequentes do DP ainda não são alvo das pesquisas na área. Em termos dos antecedentes, podem-se subdividir 
os achados em dois grupos: variáveis individuais (conhecimento do conteúdo, eficácia, crenças e atitudes) e variáveis contextuais (mentoring, grupos de estudos colaborativos, programas formativos, pesquisa-ação e coaching).

Uma das contribuições teóricas deste estudo está em apresentar a abrangência e a demarcação conceitual do DP. O uso frequente do termo deve estar condizente com a ideia de que o fenômeno diz respeito a um processo intencional e contínuo de aquisição e aperfeiçoamento de conhecimentos, habilidades e atitudes dos trabalhadores, com reflexo no desempenho dos mesmos. O maior entendimento do significado do DP também permite aos estudiosos da área ampliar o entendimento acerca do tema e aprofundar as pesquisas sobre o fenômeno, refinando elaborações teóricas para seu uso.

Os resultados desse estudo também fornecem implicações práticas para aqueles que trabalham com a temática, na medida em que permite clarear o fenômeno do DP e manter uma unidade conceitual em seu uso. Nesse sentido, pesquisadores, estudantes, trabaIhadores e gestores podem fazer um uso mais adequado do termo, guardando as similitudes existentes entre o mesmo e os conceitos de desenvolvimento de competências e desenvolvimento de carreira. Espera-se, portanto, que este estudo conduza a uma reflexão crítica acerca do conceito de DP, considerando-se que tal fenômeno pode ter importantes contribuições para os indivíduos, as organizações e a sociedade como um todo. O presente artigo também apresenta potencial para contribuir com pesquisadores e profissionais que atuam nas áreas de orientação profissional e de carreira, uma vez que permite reflexões sobre o conceito e suas interfaces.

Apesar de fornecer tais contribuições, o estudo aqui apresentado também tem algumas limitações. Um dos passos da análise conceitual realizada contemplou uma pesquisa de caráter ainda exploratório com trabalhadores e com experts no assunto para investigação do sentido atribuído ao DP. Recomendamos, contudo, que sejam feitas outras pesquisas que permitam aprofundar o entendimento e o significado atribuído ao DP, por exemplo, por meio de pesquisas de representações sociais acerca do construto. Também seriam importantes estudos que ampliassem a rede nomológica do DP, explorando variáveis individuais e contextuais ainda pouco investigadas. Por fim, sugerimos novas pesquisas que considerem o DP como variável consequente ou que permitam expandir sua compreensão a partir da investigação dos processos subjacentes ao fenômeno, com a inclusão de modelos com variáveis moderadoras e mediadoras.

\section{Referências}

Abbad, G., \& Borges-Andrade, J. E. (2014). Aprendizagem humana nas organizações e trabalho. In J. C. Zanelli, J. E. Borges-Andrade, \& A. V. B. Bastos (Orgs.), Psicologia, organizações e trabalho no Brasil. (pp. 244-284). Porto Alegre: Artmed.

Abbad, G., Loiola, E., Zerbini, T., \& Borges-Andrade, J. E. (2013). Aprender em organizações e no trabalho. In L. O. Borges \& L. Mourão (Orgs.), O trabalho e as organizações: atuações a partir da Psicologia (pp. 497-527). Porto Alegre: Artmed.

Ambiel, R.A.M. (2014). Adaptabilidade de carreira: uma abordagem histórica de conceitos, modelos e teorias. Revista Brasileira de Orientação Profissional, 15(1), 15-24. Recuperado de http://pepsic.bvsalud.org/scielo.php?script=sci_arttext\&pi$\mathrm{d}=$ S1679-33902014000100004\&lng=pt\&ting=pt

Aranha, A. V. S. (2001). Formação profissional nas empresas: locus privilegiado da educação do trabalhador? In S. M. Pimenta \& M. L. Côrrea (Orgs.), Gestão, trabalho e cidadania (pp. 281-294). Belo Horizonte: Autêntica.

Barbier, J. M., Chaix, M. L., \& Demailly, L. (1994). Éditorial. Recherche et Formation, 17, 5-8. Recuperado de http://ife.ens-lyon.fr/publications/edition-electronique/recherche-et-formation/RR017.pdf

Baruch, Y. (2004). Transforming careers: from linear to multidirectional careers paths. Career Development International, 9(1), 58-73. doi: 10.1108/00483480310460234

Borges-Andrade, J. E., Zerbini, T., Abbad, G., \& Mourão, L. (2013). Treinamento, desenvolvimento e educação: um modelo para a sua gestão. In L. O. Borges \& L. Mourão (Orgs.), O trabalho e as organizações: atuações a partir da Psicologia (pp. 465-496). Porto Alegre: Artmed.

Campos, K. C. L. (2011). Construção de uma escala de empregabilidade: definições e variáveis psicológicas. Estudos de Psicologia, 28(1), 45-55. doi: 10.1590/S0103-166X2011000100005

Castro, C. M. (2008). O ensino médio: órfão de idéias, herdeiro de equívocos. Ensaio: Avaliação Políticas Públicas Educacionais, 16(58), 113-124. Recuperado de http://www.scielo.br/pdf/ensaio/v16n58/ a08v1658.pdf

Coelho-Junior, F. A., Meneses, P. P. M., Almeida, R. F., \& Bernardo, A. J. (2015). How conceptual analysis can contribute to the theoretical refinement in organizational theories? Business and Management Review, 4(5), 247-255. Recuperado de http://www.businessjournalz.org/Brazil\%20Special\%20Edition/SI\%20January,\%202015/ BMR(0134)-V4-N5-January-2015-SI-III-23.pdf

Coelho-Junior F. A., \& Mourão, L. (2011). Suporte à aprendizagem informal no trabalho: uma proposta de articulação conceitual. Revista de Administração Mackenzie, 12(6), 224-253. doi: 10.1590/ S1678-69712011000600010

Day, C. (2001). Desenvolvimento profissional de professores: os desafios de aprendizagem permanente. Porto, Portugal: Porto Editora.

Dutra, J. S. (2004). Competências: conceitos e instrumentos para gestão de pessoas na empresa moderna. São Paulo: Gente.

Ferreira, A. B. H. (2001). Novo Aurélio Século XXI: o Dicionário da Língua Portuguesa. ( $4^{\mathrm{a}} \mathrm{ed}$., rev. e ampl.). Rio de Janeiro, RJ: Nova Fronteira.

Flach, L., \& Antonello, C. S. (2010). A teoria sobre aprendizagem informal e suas implicações nas organizações. Revista Eletrônica de Gestão Organizacional, 8(2), 193-208. Recuperado de http://www.revista.ufpe.br/gestaoorg/index.php/gestao/article/ viewFile/195/176 
Gondim, S. M. G., Souza, J. J., \& Peixoto, A. L. A. (2013). Gestão de pessoas. In L. O. Borges \& L. Mourão. (Orgs.), As pessoas, o trabalho e as organizações: intervenções a partir da Psicologia (pp. 343-374). Porto Alegre: Artmed.

Guskey, T. (2000). Evaluating professional development. Thousand Oaks: Corwin Press.

Hall, D. T. (1976). Career in organizations. Glenview: Scott Foresman.

Hill, H. C., Beisiegel, M., \& Jacob, R. (2013). Professional development research: consensus, crossroads, and challenges. Educational Researcher, 42(9), 476-487. doi: 10.3102/0013189X13512674

Ho, T. V., Nakamori, Y., \& Ho, B. T. (2013). Study on a model for teacher professional development in Vietnam based on knowledge management. In Proceedings of the 57th Annual Meeting of the ISSS. HaiPhong, Vietnam. Recuperado de http://journals.isss.org/index. php/proceedings57th/article/viewFile/2020/691

Houaiss, A., \& Villar, M. S. (2009). Dicionário Houaiss da Língua Portuguesa. Rio de Janeiro, RJ: Objetiva.

Illeris, K. (2007). What do we actually mean by experiential learning? Human Resource Development Review, 6(1), 84-95. doi: $10.1177 / 1534484306296828$

Kolb, D. (1984). Experiential learning. Englewood Cliffs, New Jersey: Prentice.

Le Boterf, G. (1994). De la compétence: essai sur un attracteur étrange. Paris: Éditions Organisation.

Lent, R.W., Brown, S. D., \& Hackett, G. (1994). Toward a unifying social cognitive theory of career and academic interest, choice, and performance. Journal of Vocational Behavior, 45(1), 79-122. doi: 10.1006/jvbe.1994.1027

Machado, A., \& Silva, F. J. (2007). Toward a richer view of the scientific method the role of conceptual analysis. American Psychological Association. 62(7), 671-681. doi: 10.1037/0003-066X.62.7.671

Magalhães, M. O., \& Bendassolli, P. F. (2013). Desenvolvimento de carreiras nas organizações. In L. O. Borges \& L. Mourão (Orgs.), $O$ Trabalho e as organizações: atuações a partir da psicologia (pp. 433-460). Porto Alegre: Artmed.

McClelland, D. C. (1973). Testing for competence rather than for "intelligence". American Psychologist, 28(1), 1-14. Recuperado de https:// www.therapiebreve.be/documents/mcclelland-1973.pdf

Monteiro, A. C. F., \& Mourão, L. (2017). Desenvolvimento profissional: a produção científica nacional e estrangeira. Revista Psicologia: Organizações e Trabalho, 17(1), 39-45. doi: 10.17652/ rpot/2017.1.12246

Mourão, L., Monteiro, A. C. F., \& Viana, V. R. (2014). A Influência do desenvolvimento profissional e da identificação organizacional na satisfação no trabalho. Psico, 45(2), 198-208. doi: 10.15448/1980-8623.2014.2.13470

Mourão, L., Puente-Palacios, K., Porto, J. B., \& Monteiro, A. C. F. (2015). Percepção de desenvolvimento profissional. In K. Puente-Palacios \& A. L. A. Peixoto (Orgs.), Ferramentas de diagnóstico para organizações e trabalho: um olhar a partir da psicologia (pp. 315-326). Porto Alegre: Artmed.

Nonaka, I., \& Takeuchi, H. (1997) Criação do conhecimento na empresa: como as empresas japonesas geram a dinâmica da inovação. Rio de Janeiro: Campus.

Oliveira, M. C. D., Melo-Silva, L. L., \& Coleta, M. F. D. (2012). Pressupostos teóricos de super: datados ou aplicáveis à psicologia vocacional contemporânea?. Revista Brasileira de Orientação Profissional, 13(2), 223-234. Recuperado de http://pepsic.bvsalud.org/scielo.php?script=sci_arttext\&pi$\mathrm{d}=$ S1679-33902012000200009\&lng=pt\&tlng=pt

Paquay, L., Wouters, P., \& Van Nieuwenhoven, C. (2012). A avaliação, freio ou alavanca do desenvolvimento professional? In L. Paquay, $\mathrm{P}$. Wouters, \& C. Van Nieuwenhoven (Orgs.), A avaliação como ferramenta do desenvolvimento profissional de educadores (pp. 13-39). Porto Alegre: Penso.

Perrenoud, P. (1999). Construir competências desde a escola. Porto Alegre: Artmed.

Petocz, A., \& Newbery, G. (2010). On conceptual analysis as the primary qualitative approach to statistics education research in psychology. Statistics Education Research Journal, 9(2), 123-145. Recuperado de http://www.stat.auckland.ac.nz/serj

Ponte, J. P. (1994). Knowledge, beliefs, and conceptions in mathematics teaching and learning. In L. Bazzini (Org.), Proceedings of the fifth international conference on systematic cooperation between theory and practice in mathematics education (pp. 169-177). Pavia: ISDAF.

Portaria Normativa no 17 (2009, 28 de dezembro). Coordenação de Aperfeiçoamento de Pessoal de Nível Superior [Capes]. Dispõe sobre o mestrado profissional no âmbito da Fundação Coordenação de Aperfeiçoamento de Pessoal de Nível Superior CAPES. Brasília, DF: Ministério da Educação.

Ryle, G. (1970). Introdução à psicologia: o conceito de espírito. Lisboa: Moraes Editores.

Santos, J., \& Mourão, L. (2011). Impacto do treinamento como variável preditora da satisfação com o trabalho. Revista de Administração, 46(3), 305-318. doi:10.1590/S0080-21072011000300008

Savickas, M. L. (2013). The theory and practice of career construction. In S. D. Brown \& R. W. Lent (Orgs.), Career development and counselling: Putting theory and research to work. (2a ${ }^{\mathrm{a}}$ ed., pp. 147-183). Hoboken: Wiley.

Savickas, M. L., Nota, L., Rossier, J., Dauwalder, J-P., Duarte, M. E., Guichard, J., Soresi, S., ... Van Vianen, A. (2009). Life designing: A paradigm for career construction in the 21 st Century. Journal of Vocational Behavior, 75(3), 239-250. doi: 10.1016/j.jvb.2009.04.004

Sonnentag, S., Niessen, C., \& Ohly, S. (2004). Learning at work: Training and development. International Review of Industrial and Organizational Psychology, 19, 249-289. doi: 10.1002/0470013311.ch8

Sparks, D., \& Loucks-Horsley, S. (1990). Models of staff development. In W. R. Houston (Org.), Handbook of research on teacher education (pp. 234-251). Nova lorque: McMillan.

Super, D. E. (1990). A life-span, life-space approach to career development. In D. Brown, L. Brooks \& Associates (Orgs.), Career choice and development (pp. 197-261). San Francisco: Jossey-Bass.

VandenBos, G. R. (Org.). (2010). Dicionário de Psicologia da American Psychological Association. Porto Alegre: Artmed.

Walker, L. O., \& Avant, K. C. (1988). Strategies for theory construction in nursing (2ª ed.) Califórnia: Appleton \& Lange.

Weiszflog W. (Org.). (2015). Michaelis Dicionário Brasileiro da Língua Portuguesa On-Line. Recuperado de http://michaelis.uol.com.br/ busca? $r=0 \& \mathrm{f}=0 \& \mathrm{t}=0$ \& palavra $=$ profissional

Wilson, J. (2005). Pensar com conceitos (2 $2^{\mathrm{a}}$ ed.). São Paulo: Martins Fontes.

Zarifian, P. (2001). Objetivo competência: por uma nova lógica. São Paulo: Atlas.

Zibas, D. M. L. (2005). A reforma do ensino médio nos anos de 1990: o parto da montanha e as novas perspectivas. Revista Brasileira de Educação, 28, 24-36. doi: 10.1590/S1413-24782005000100003 
Luciana Mourão, Doutora em Psicologia pela Universidade de Brasília (UnB), com estágio pós-doutoral no Instituto Universitário de Lisboa (ISCTE/IUL), é Professora titular no Programa de Pós-Graduação em

Psicologia da Universidade Salgado de Oliveira (Universo)

Endereço para correspondência: Rua Marechal Deodoro, 263 -

Centro. Campus Niterói - $2^{\circ}$ andar. Niterói - RJ. CEP 24030-060.

E-mail: mourao.luciana@gmail.com

Ana Cláudia Monteiro, Doutora em Psicologia pela Universidade Salgado de Oliveira (Universo), é Professora da Universidade Salgado de Oliveira (Universo). E-mail:anamonteiropsi@gmail.com

Recebido em 18.Mai.17 Revisado em 11.Mar.18

Aceito em 20.Abr.18 